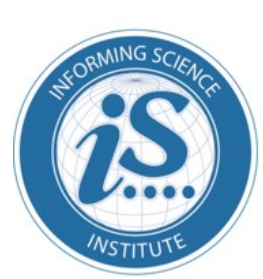

\title{
Informing Science:
} the International Journal of

an Emerging Transdiscipline

An Official Publication

of the Informing Science Institute

InformingScience.org

Inform.nu

Volume 20, 2017

\section{The Utilisation of SMARTPHONES Apps as A SERVICE TOOL AT KUWAITI ACADEMIC LIBRARIES}

Husain F. Ghuloum*

Zuwainah Al-lamki

* Corresponding author
College of Basic Education, Department of Library and Information Science, PAAET, Kuwait.

College of Basic Education, Department of Library and Information Science, PAAET, Kuwait. hf.ghuloum@paaet.edu.kw

zr.allamki@paaet.edu.kw

\section{ABSTRACT}

Aim/Purpose

This paper aims to investigate how Kuwaiti Academic Libraries (KALs) have responded to the rapidly evolving Smartphone-Apps (SP-Apps) environment, as well as exploring the level of electronic services provided in these libraries.

Background This study can illustrate whether the governmental, academic libraries in the State of Kuwait have already benefited from the mobile services provided by smart phones or not.

Methodology

In this study, the researchers use both qualitative and quantitative methods. Therefore, questionnaires and interviews are used in order to collect in-depth data in this field. The questionnaire sample was 400 respondents. They divided in two KALs: Kuwait University Library (KUL) and Public Authority of Applied Education Training Library (PAAETL), while eight individual interviews were conducted one-to-one in this research.

Contribution This paper may be important for academic libraries to identify shortcomings in the smartphones' content and services they provide and in highlighting efforts by libraries to address their users' needs in this area.

Findings The findings show that most participants expressed the need to introduce an SPApp to their library. They also confirmed that there are many difficulties in creating an SP-App including lack of budget, lack of awareness of library management, lack of clarity about library management strategic objectives, and vision for an SP-App.

Recommendations Designing SP-Apps that have reliable content and user interface that is easy to use for Practitioners is a considerable challenge. For this reason, the study highly recommends introducing SP-Apps for KALs as soon as possible.

Accepting Editor Peter Rittgen | Received: December 14, 2016 | Revised: March 29, May 8, May 16, 2017 | Accepted: June 9, 2017.

Cite as: Ghuloum, H. F., \& Al-lamki, Z. (2017). The utilisation of smartphones apps as a service tool at Kuwaiti academic libraries. Informing Science: the International Journal of an Emerging Transdiscipline, 20, 133-148. Retrieved from http://www.informingscience.org/Publications/3766

(CC BY-NC 4.0) This article is licensed to you under a Creative Commons Attribution-NonCommercial 4.0 International License. When you copy and redistribute this paper in full or in part, you need to provide proper attribution to it to ensure that others can later locate this work (and to ensure that others do not accuse you of plagiarism). You may (and we encourage you to) adapt, remix, transform, and build upon the material for any non-commercial purposes. This license does not permit you to use this material for commercial purposes. 
Utilisation of Smartphones' Apps as a Service Tool

Future Research The recommendations proposed are relevant to Kuwait. Further research may be useful in this field in other developing countries, in order to test or develop the suggested strategy.

Keywords academic library, smartphone, information communication technology, Kuwait

\section{INTRODUCTION}

Mobile access is in greater demand than ever before by library users. Smartphone Applications (SPApps) are becoming the preferred way to access almost any type of information. In fact, today SPApps are used widely in higher education institutions. Academic libraries, in the age of the web 2.0, have an exciting opportunity to engage their users in new and dynamic ways. Providing mobile services allows academic libraries to remain relevant and ahead of the curve in an ever growing mobile society. Kuwait has also benefited from SP-Apps. Today, the Kuwaiti government has an SP-App called "Kuwait Government Online (KGO) Portal". This application provides a mobile means to use the portal and benefit from many government services. Such services include query and information services and electronic payment via Government E-Payment System, which is supervised by the Ministry of Finance. Furthermore, to receive portal tweets and information on the application, users are sent updated e-Government visual news and awareness material on their smart-handheld devices (Kuwait Government Online, 2015). In line with the Kuwaiti government's plan to include all sectors of the State under this portal, decision-makers in state-supported higher education institutions also seek to address such needs. Hence, this study investigates how governmental Kuwaiti Academic Libraries (KALs) have responded to the rapidly evolving SP-Apps environment, as well as explores the level of electronic services (e-services) they provide.

\section{SMARTPHONES ADOPTION IN HIGHER EDUCATION INSTITUTIONS}

Many studies have shown that Smartphones are increasingly the preferred choice for web access among students. Bomhold (2013) noted that students are using smartphones in their daily lives; therefore, implementing mobile learning strategies in the classroom would satisfy students' desire to extend their use of smartphones into their learning environment. In 2013, EDUCAUSE Center for Analysis and Research (ECAR) collaborated with more than 250 higher education institutions in the USA, Canada, and other countries to collate responses from more than 112,000 undergraduate students about their technology experiences and expectations. The findings showed that $76 \%$ of participants had used smartphones for academic purposes. Moreover, the survey indicated that students were ready to use their smartphones more for academic purposes, and they looked to institutions and instructors for opportunities and encouragement to do so (Dahlstrom, Walker, \& Dziuban, 2013). Chen and Denoyelles (2013) collected data from 1,082 students in 12 different colleges at the University of Central Florida (UCF), in order to explore students' mobile learning practices in higher education. The study findings indicated that among all the students, who had access to mobile devices, more than half reported that they used smartphones for academic purposes. This result is expected, while several practical barriers keep students from using smartphones as an academic tool. According to Dahlstrom et al. (2013, p. 29), "inadequate battery life, slow network connections and device usability concerns were the top-three limitations of smartphone as academic tools" (see Figure 1). 
Ghuloum \& Al-lamki

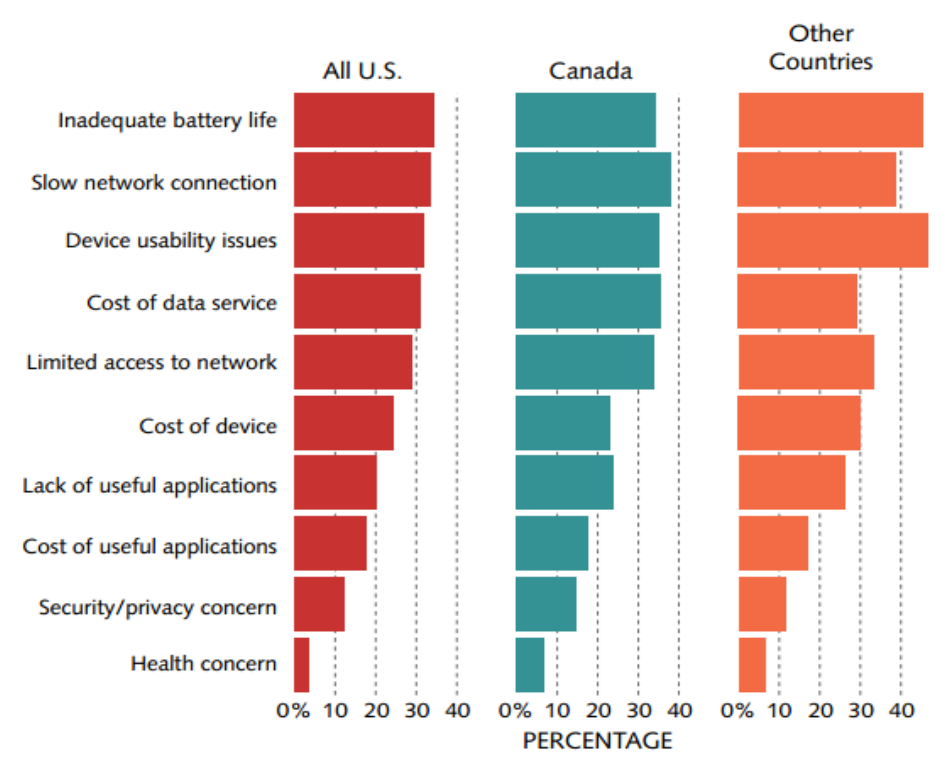

Figure 1: Barriers to using smartphones as learning tools (Dahlstrom, Walker \& Dziuban, 2013, p. 30)

\section{SMARTPHONES APPS (SP-APPS) FOR ACADEMIC LIBRARIES}

Before discussing SP-Apps for academic libraries, it is necessary to define Application (App). An "App" is software that performs particular functions for users. The term is particularly popular in the context of mobile devices such as iPhone, iPad, Android, and other smart devices (Douglas \& Melody, 2012). An App is usually accessed by tapping on an icon on the home screen of smart devices. There is no need to search for a program or key in the address of a website, which means it is very easy to use. Thus, many academic libraries make their software and websites available in an App form, making it easier for users to find and use their e-services. For example, University of Leeds has launched two Apps:

1. "UniLeeds" offers a range of services to students, staff and visitors.

2. "Blackboard Mobile Learn" provides mobile access to the University's Virtual Learning Environment (VLE).

"UniLeeds" offers a set of tasks and options, which was selected based on student feedback (see Figure 2).

The "UniLeeds" is designed to work on most popular smartphones, such as iPhone, Android, and BlackBerry devices, and provides mobile web pages for other operating systems (Caperon, 2015). Users can access "UniLeeds" to view their library records, online catalogue, and e-services, as well as information on fines, book renewal, and the opening hours of university library facilities.

Another good example is the Harvard University application. The "Mobile Harvard", or "MHarvard", which is a university-wide initiative to improve the mobile experience of students, faculty, staff, visitors, and those who interact with Harvard's campus and community. Established in January 2013, "M-Harvard 2.0" is the latest version of the application with a number of functional, design, and content enhancements. "M-Harvard 2.0" now includes native applications for Android and iOS operating systems, as well as mobile web application access to any web-enabled smartphone (Harvard University, 2015). In the "M-Harvard App", users can access all e-services including databases, ejournals, and e-books. Furthermore, they can ask a librarian directly, find the latest news and events about the library, and search the catalogue. 


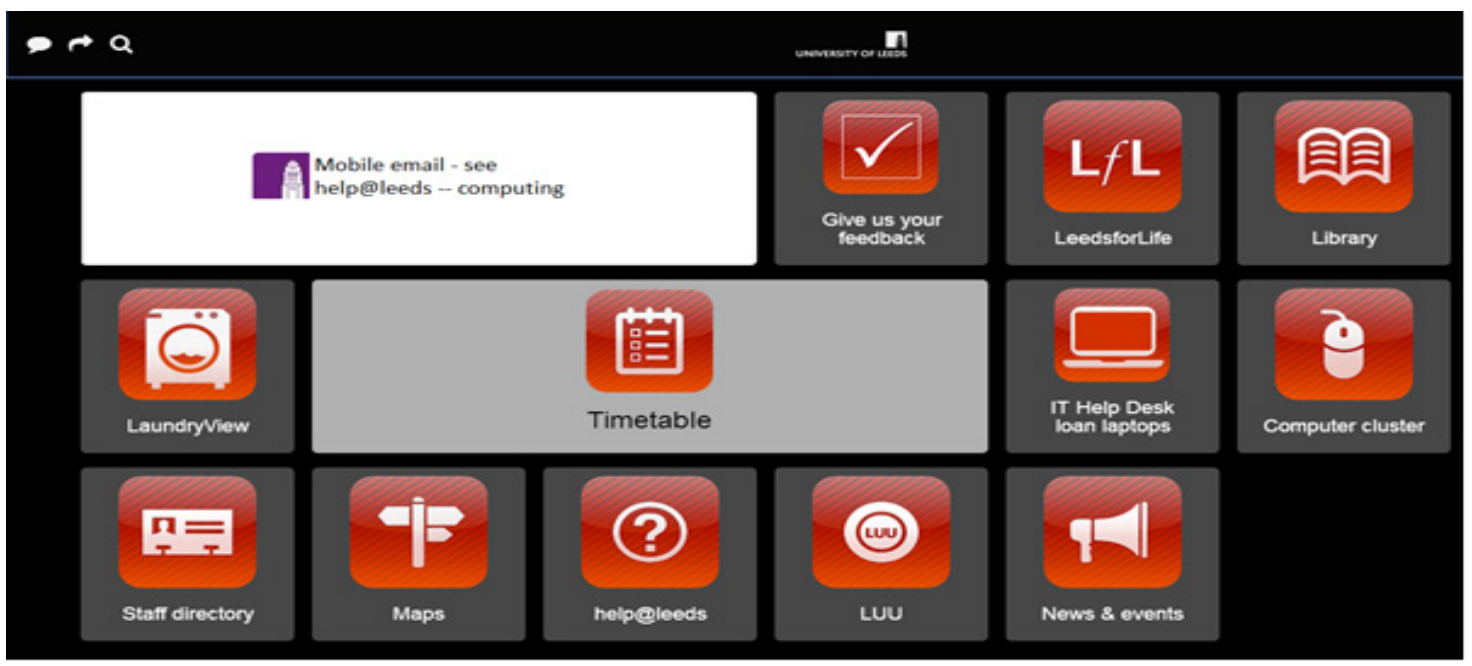

Figure 2: Options available on the UniLeeds mobile App. (Caperon, 2015, p.6)

In relation to user satisfaction with library m-services, California Digital Library (CDL) conducted two surveys and collected responses from 295 participants and 14 interviews. The finding showed that smartphone users use the library services to find known materials of information, and they are normally already using online databases and catalogues on their mobile devices. In other words, there appeared to be a need among users to transfer data between devices, such as search results to primary computers. In addition, $55 \%$ of respondents preferred to search the library catalogue on their mobile frequently or occasionally (Meier, 2010). In the same vein, Cambridge University conducted a survey and found that $55 \%$ of respondents favoured accessing the library catalogue from a smartphone (Mills, 2009).

App use is not confined to Western universities. Some Arab countries have already created special Apps for their academic libraries. For instance, United Arab Emirates University (UAEU) has devoted much time and effort introducing mobile technologies for teaching and learning services. Operators of the project released their first mobile App a few years ago and last year they enhanced and released the first truly native mobile application. (UAE University, 2016)

The current enhanced mobile App introduces new real-time information and services that support students in their academic programmes and student life. This will play a strategic role and is in line with the university's goal of placing students at the centre of university experience. It is also aligned with the UAE Smart Government vision. UAEU mobile App provides many services, including library services such as browsing library catalogues, renewing books, requesting documents, checking availability, and asking a librarian, as well as information on library opening hours, current awareness, and online search services (UAE University, 2016).

Alosaimi, Alyahya, Alshahwan, Al Mahyijari, and Shaik (2016) investigated the prevalence and correlates of smartphone addiction among university students in Saudi Arabia. In the study, the librarians at King Fahad University confirmed that "the use of electronic services have increased after they applied smart phone application". Some librarians in Saudi Arabian universities stated that they faced some difficulties applying SP-Apps including budget, ICT literacy, infrastructure, qualified staff, and maintenance (Alosaimi et al., 2016).

The literature review results demonstrate the importance of activating mobile services in academic libraries among students. In addition, there are some difficulties when academic libraries seek to apply SP-Apps. Consequently, this study identifies the mobile services needed in governmental KALs. Furthermore, it explores users' satisfaction with these services. 


\section{METHODOLOGY}

Several studies confirm that the definition of the research questions is one of the most important steps to be taken when designing a study (Kuzel, Engel, Addison, \& Bogdewic, 1994; Walsham, 1995; Yin, 2009). Therefore, the research questions are linked directly to the aim of the study.

- What is the users' satisfaction with e-services provided by governmental KALs?

- What are the desired features of e-services in governmental KALs?

- Why is it important to establish an SP-App in governmental KALs?

- What are the main barriers, if any, that may hinder building an SP-App for KALs?

Researchers in this study used both qualitative and quantitative methods. The qualitative research method was used because of the basic philosophical assumption of people's behaviour and experience, which are of importance in this paper. The quantitative research method provided a significant amount of data and feedback, in addition to easy access to the participants at a low cost. Hence, interviews and questionnaires were used to collect in-depth data.

Participants in the current research project were drawn from two governmental academic libraries in Kuwait: Kuwait University Library (KUL) and Public Authority for Applied Education and Training Library (PAAETL). Eight hundred users (undergraduate students) participated in the questionnaire, and eight interviews were conducted with the staff responsible for electronic services in both libraries (KUL and PAAETL)

\section{QUESTIONNAIRE}

The questionnaire is divided into four main sections. The first section aims to collect data related to the demographic profile and the libraries' usage. The second section obtains data related to the satisfaction of the respondents regarding the e-services offered to them. The third section collects data on the importance of using SP-Apps in libraries, and the last section seeks reasons from those registered users who had never taken advantage of the e-libraries' services at all. The questionnaire sample consisted of 800 respondents (undergraduate students) from two university libraries (KUL and PAAETL). From February to June 2016, the questionnaires were sent out to both libraries. All questionnaires were returned. The questionnaire sample was undergraduate students, in order to achieve a balance between participants' responses. A non-probability sample was used because it is difficult to find an accurate representation of the total population. The researchers explained fully and clearly what the research was about and how it would be disseminated. Moreover, they gained the participants' permission before distributing the questionnaire.

Because the two libraries seem to have different problems with both users and libraries, researchers will be dealing with these issues separately in the discussion section. They will focus on the common issues in one section and the unique issues in another section.

\section{DEMOGRAPHIC PROFILE}

This part of the questionnaire seeks to identify the participants' profiles, in order to present clearly the percentages.

\section{Participants}

The findings show that of the 800 participants divided into two libraries, 435 (54.4\%) were female, while 365 (45.6\%) were male. (see Table 1) 
Table 1: Participants' profiles

\begin{tabular}{|c|c|c|c|c|}
\hline \multicolumn{2}{|l|}{ University } & \multicolumn{3}{|c|}{ Undergraduate Students } \\
\hline & & Male & Female & Total \\
\hline \multirow[t]{2}{*}{ KUL } & Count & 179 & 221 & 400 \\
\hline & $\%$ of Total & $44.8 \%$ & $55.2 \%$ & $100 \%$ \\
\hline \multirow[t]{2}{*}{ PAAETL } & Count & 186 & 214 & 400 \\
\hline & $\%$ of Total & $46.5 \%$ & $53.5 \%$ & $100 \%$ \\
\hline \multirow[t]{2}{*}{ TOTAL } & Count & 365 & 435 & 800 \\
\hline & $\%$ of Total & $45.6 \%$ & $54.4 \%$ & $100 \%$ \\
\hline
\end{tabular}

\section{Library usage}

Figure 3 shows that, with regard to KUL, of the 400 participants, $83(20.75 \%)$ never used e-services in their libraries. The remaining $317(79.25 \%)$ respondents had used them. However, the proportions of library users were distributed as follows: $39(12.30 \%)$ used the library every day, $113(35.64 \%)$ 2-3 times per week, $87(27.44 \%)$ once a week, 51(16.08\%) once a month and $27(8.51 \%)$ less than once a month. Regarding PAAETL, the results show that of the 400 undergraduate students, 172 (43\%) never used e-services in their libraries, while $228(57 \%)$ had used them. The proportions of library users were distributed as follows: $21(9.21 \%)$ used the library every day, $57(25 \%) 2-3$ times per week, $89(39.03 \%)$ once a week, 32(14.03\%) once a month and $29(12.71 \%)$ less than once a month.

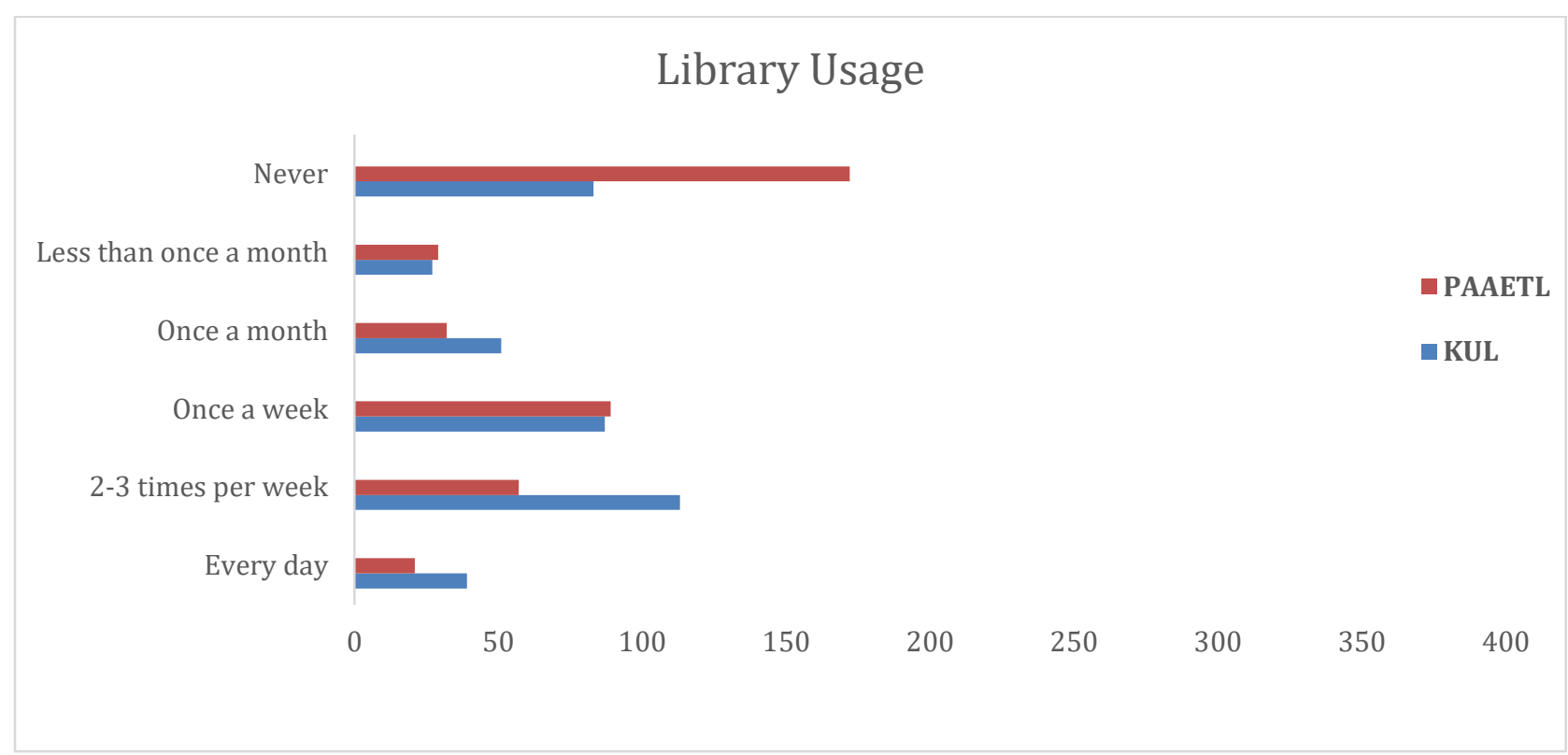

Figure 3: Library usage of 400 students

The result confirms that a number of participants did not use their e-services in both libraries. Consequently, a question is asked at the end of questionnaire to identify the reasons for this. 


\section{USER SATISFACTION WITH ELECTRONIC SERVICES}

This part of the questionnaire seeks to obtain results on the satisfaction of the respondents regarding the e-services offered. Only the opinions of $545(68.12 \%)$ respondents who used e-services in their libraries were analysed (see Figure 4).

\section{E-services use in the library}

This question seeks to identify the percentage of students who regularly use e-services in their libraries. Participants can choose more than one answer. In KUL, as shown in Figure 4, the finding shows that most participants [312, which is 99\%] used "Internet services", 293 (92.43\%) "library e-catalogue", 157 (49.53\%) "Reference services", 271 (85.49\%) "online database", 188 (59.31\%) "E-journals", and 127 (40.06\%) "E-books". In PAAETL, the results are different: 218 (95.61\%) preferred to use "Internet services", 112 (49.12\%) library e-catalogue, 54 (23.68\%) "Reference services", 53 (23.25\%) "online database", $74(32.46 \%)$, "E-journals", and $42(18.42 \%)$ "E-books".

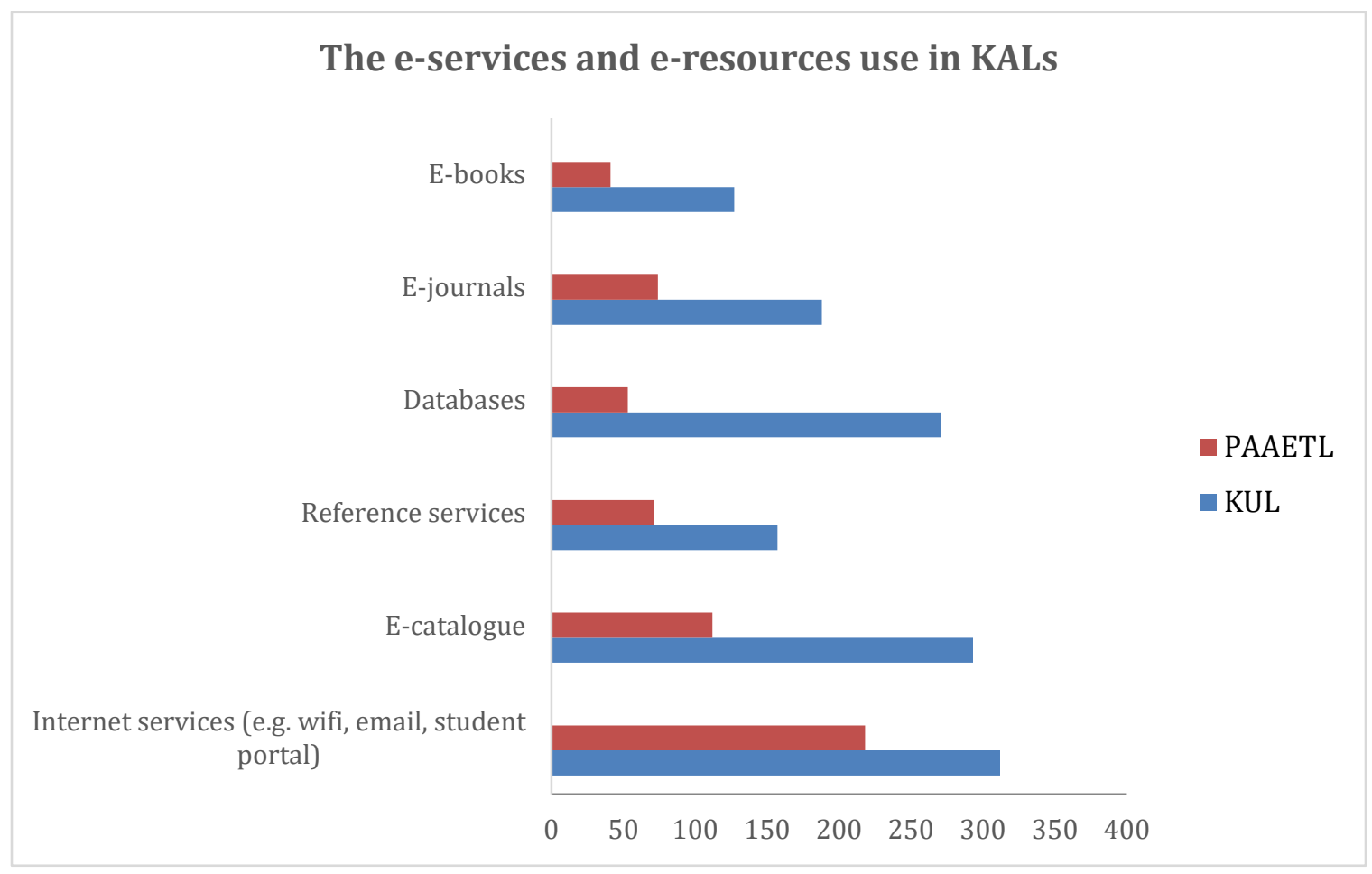

Figure 4. The e-services and e-resources use from 400 students in KAL

\section{The level of electronic services in the Kuwaiti Academic Libraries (KALs)}

This question sought to identify, in general, the viewpoint of the respondents towards the e-services offered by both libraries. Starting with KUL, as shown in Table 2, the findings show that $51(16.08 \%)$ thought it was "Poor", whereas 97 (30.60\%), 113 (35.64\%) and $56(17.66 \%)$ respondents said it was "Satisfactory", "Good" and "Excellent", respectively. On the other hand, the findings for PAAETL show that the majority of respondents thought it was "Poor" (109; 47.80\%), otherwise it was "Satisfactory" $(70 ; 30.70 \%)$ or "Good" $(31 ; 13.59 \%)$. An insignificant number indicated that the level of services was "Excellent" (18; 7.89\%). 
Table 2: The level of e-services in KALs

\begin{tabular}{|c|c|c|c|c|}
\hline \multicolumn{2}{|c|}{ How Do you rate the e-services in your library? } & KUL & PAAETL & Total \\
\hline \multirow[t]{2}{*}{ Poor } & Count & 51 & 109 & 160 \\
\hline & $\%$ of Total & $16.1 \%$ & $47.8 \%$ & $63.9 \%$ \\
\hline \multirow[t]{2}{*}{ Satisfactory } & Count & 97 & 70 & 167 \\
\hline & $\%$ of Total & $30.6 \%$ & $30.7 \%$ & $60.3 \%$ \\
\hline \multirow[t]{2}{*}{ Good } & Count & 113 & 31 & 144 \\
\hline & $\%$ of Total & $35.6 \%$ & $13.6 \%$ & $49.2 \%$ \\
\hline \multirow[t]{2}{*}{ Excellent } & Count & 57 & 18 & 75 \\
\hline & $\%$ of Total & $17.6 \%$ & $7.9 \%$ & $25.5 \%$ \\
\hline \multirow[t]{2}{*}{ TOTAL } & Count & 317 & 228 & 545 \\
\hline & $\%$ of Total & $58.1 \%$ & $41.9 \%$ & $100.0 \%$ \\
\hline
\end{tabular}

\section{THE IMPORTANCE OF SP-APPS IN THE KALS}

This part of the questionnaire seeks to identify the importance of the use SP-Apps in KALs.

\section{The usage of smartphone Apps}

In this question we endeavoured to identify how many participants, in both universities, used smartphone Apps in general. Regarding KUL, 393 (98.3\%) respondents said "Yes", while 7 (1.7\%) said "No". In comparison, 395 (98.7\%) participants at PAAETL said "Yes", whereas only 5 (1.3\%) said "No" (see Figure 5).

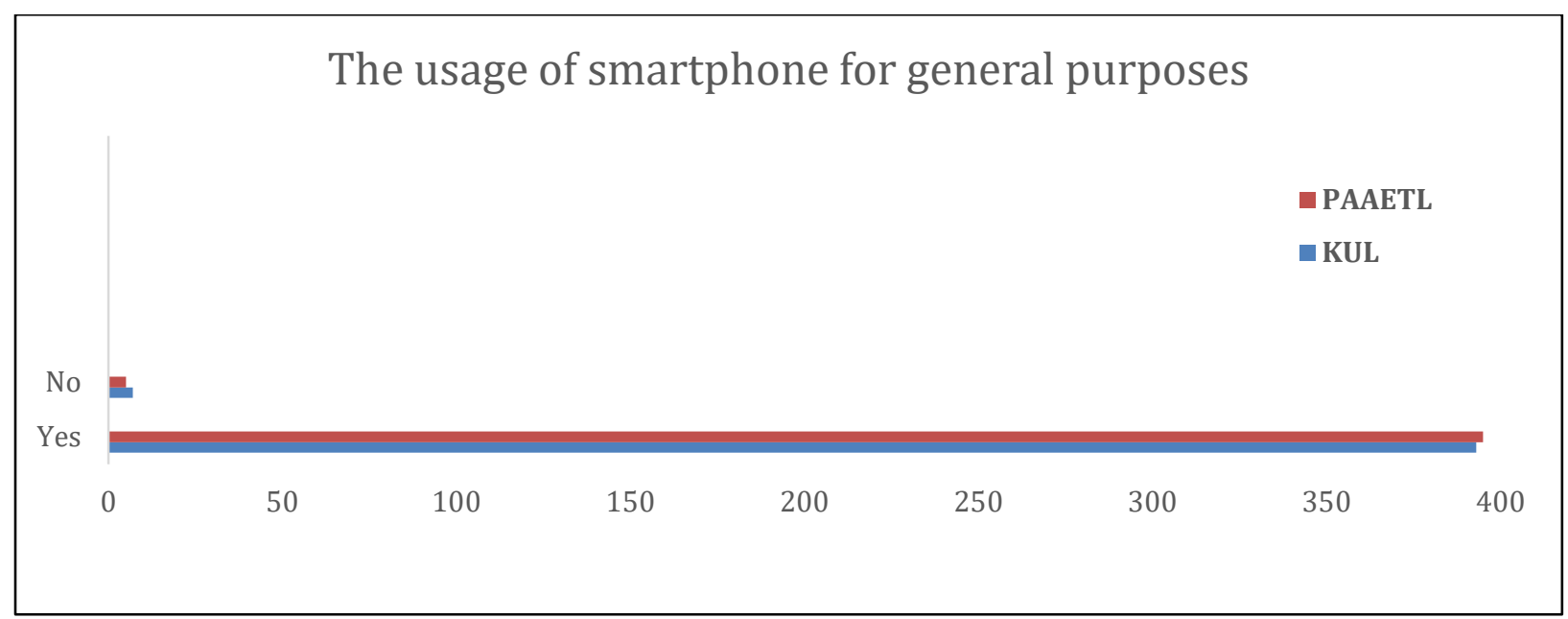

Figure 5: The usage of smartphones for general purposes.

This finding indicated that the majority of study participants used smartphones for general purposes.

\section{If yes, how often do the participants actually utilise a smartphone?}

This question seeks to identify how often the participants actually utilise the smartphone Apps. KUL respondents said very often $(219 ; 54.8 \%)$, often $(107 ; 26.7 \%)$, sometimes $(62 ; 15.5 \%)$, or rarely $(12$; $3 \%)$. Regarding PAAETL, respondents said very often $(209 ; 52.3 \%)$, often $(122 ; 30.5 \%)$, sometimes $(59 ; 14.7 \%)$ or rarely $(10 ; 2.5 \%)$ (see Figure 6$)$. 


\section{How often participants utilise the smartphones}

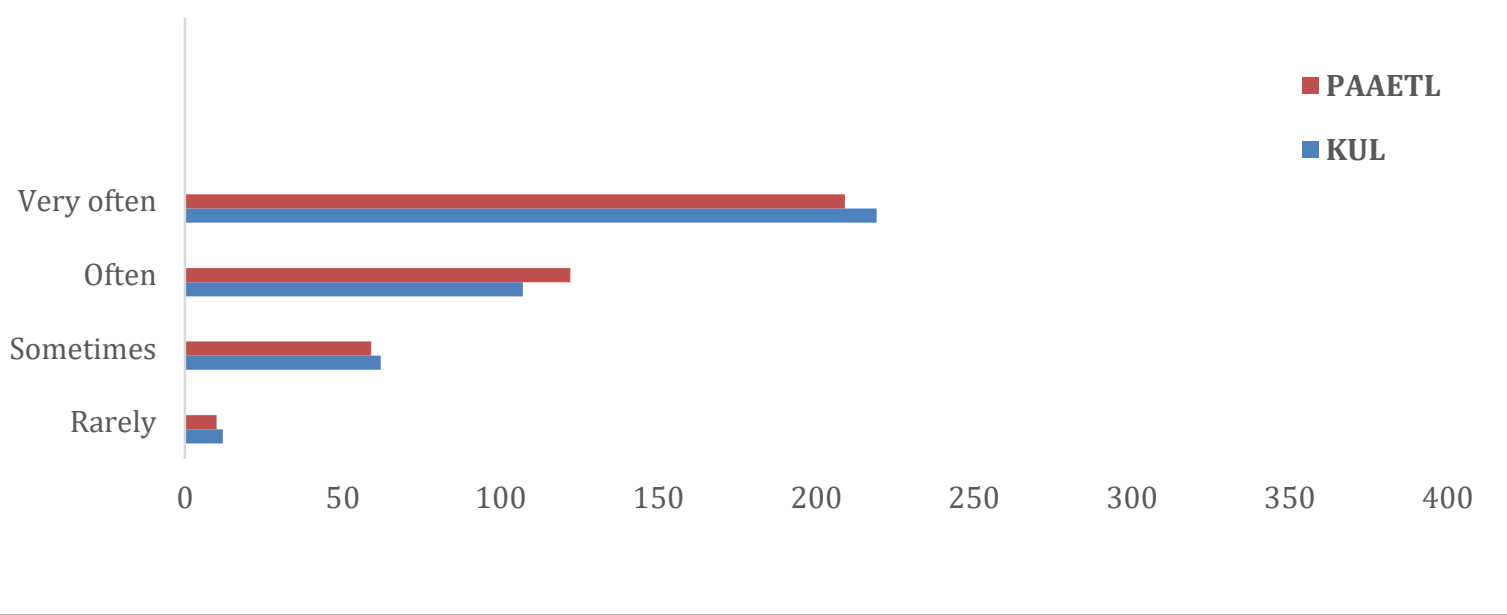

Figure 6: How often participants actually utilise a smartphone.

Do you prefer to use a smartphone when visiting your university or/and library website?

In Figure 7, 229 (57.25\%) participants in KUL said "Yes" and 171 (42.75\%) said "No". On the other hand, in PAAETL, 143 (35.75\%) respondents said "Yes" and 257 (64.25\%) said "No".

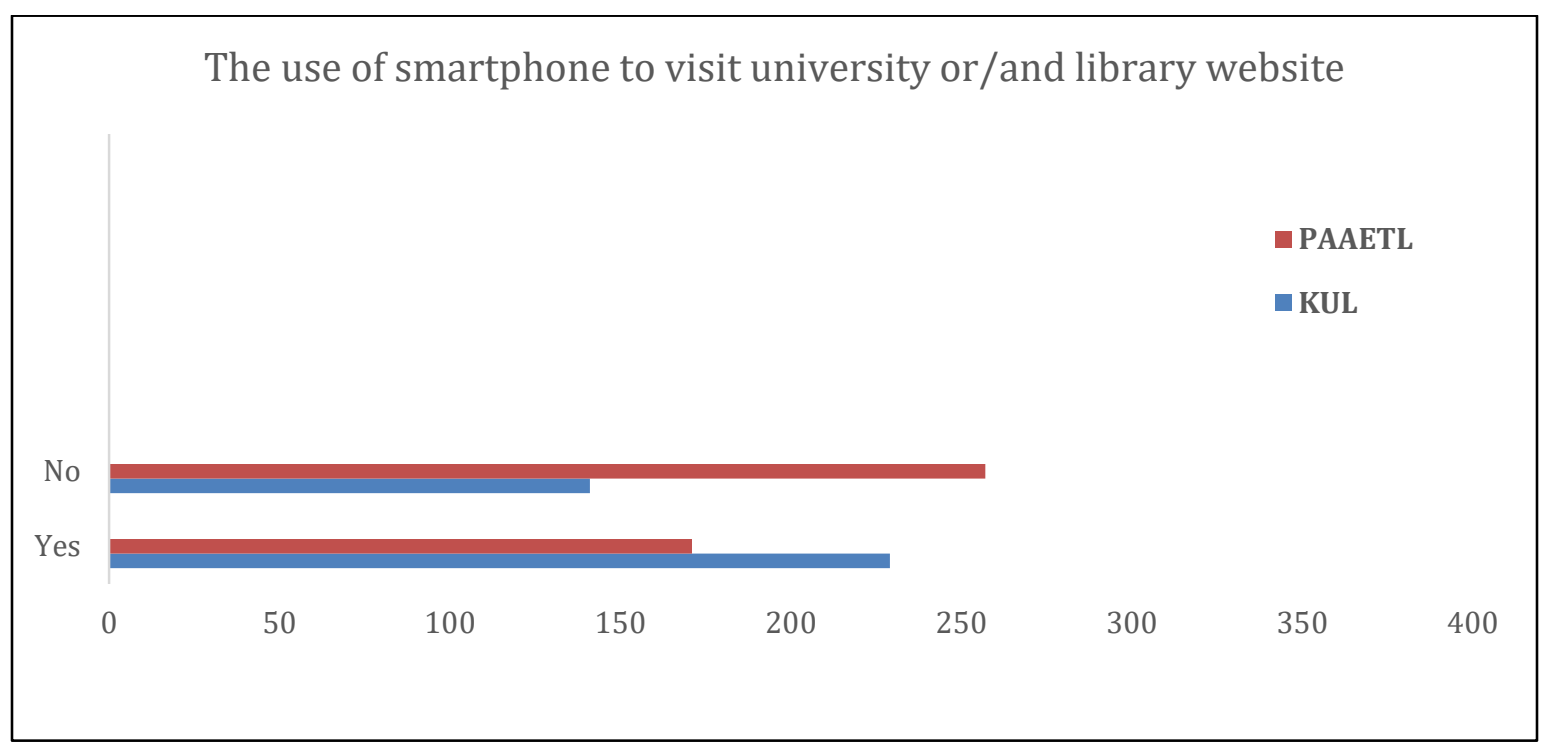

Figure 7: The use of a smartphone to visit university or/and library website.

\section{Do you think that it is essential to introduce an SP-App for your library?}

Most participants thought it was important to introduce an SP-App for their libraries. In KUL, 324 (81\%) said "Yes" and 76 (19\%) said "No". Regarding PAAETL, 297 (74.25\%) said "Yes" and 103 $(25.75 \%)$ said "No" (see Figure 8). 


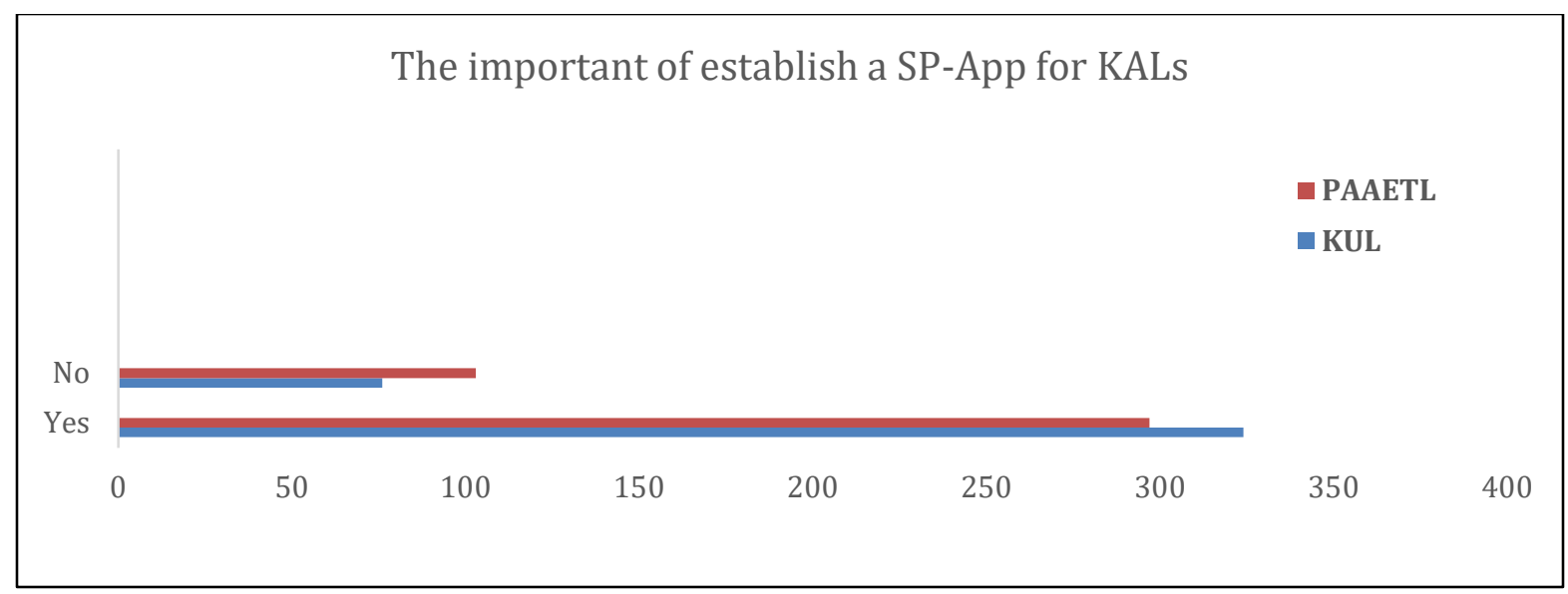

Figure 8: The importance of establishing an SP-App for KALs.

\section{If yes, why is it important?}

There were several answers, and these are some of them:

- It is very easy to use.

- We can use it $24 / 7$.

- It saves time and effort to get the information.

- It is familiar for the students.

The reasons why some registered users had never taken advantage of the e-libraries' services at all

This section sought to identify the reasons why some respondents never used electronic services in their libraries. The responses of $255(31.88 \%)$ participants who had not used e-services in their libraries were analysed. Most comments were similar:

- I do not know how to use the e-services offered in our library.

- I prefer to use Internet at home or/and another library website.

- It is not easy to use.

- I do not have experience of using electronic services in our library.

\section{MAIN FINDINGS}

\section{Common issues:}

- Both users in KUL and PAAETL prefer to use Internet services more than other services.

- The majority of participants used SP-Apps for general purposes.

- Most users in both libraries used smartphones very often.

- Most participants believe that, it is very important to introduce an SP-App to their libraries.

\section{Unique Issues:}

- The findings showed that KUL has useful e-services and resources such as e-books, ejournals, databases, reference services, and e-catalogue, while PAAETL does not.

- In general, the level of e-services in KUL is better than in PAAETL. 


\section{INTERVIEWS}

A total of eight one-to-one interviews were conducted with librarians in both KUL and PAAETL. The purpose of the interview was to explore sensitive issues and to gather detailed information about the current and future initiatives regarding mobile and electronic services provision. Researchers clarified for all interviewees the purpose of the study. Moreover, they explained to the participants that their names and responses were confidential, and that they had the freedom to decline answering any question.

In order to analyse the data from the interviews, the researchers used "Miles and Hubermann's iterative pattern coding" technique (Oates, 2006). Essential results from the interviews could be obtained through three processes: Creating interview transcripts, Generating pattern codes, and Drawing a checklist matrix.

\section{Data analysis of interview}

The data gathered from the eight librarians were analysed and presented below according to each data pattern:

Table 3: Thematic groups and data pattern

\begin{tabular}{|l|l|}
\hline Thematic Group 1: Technological Context & Electronic services (quality \& quantity) \\
\hline Data Pattern 1 & Smartphone App \\
\hline Data Pattern 2 & The budget \\
\hline Thematic Group 2: Financial Context \\
\hline Data Pattern 3 & Vision and Perception \\
\hline Thematic Group 3: Management Context & Difficulties and Barriers \\
\hline Data Pattern 4 &
\end{tabular}

\section{Technological context}

Electronic Services (Quality and Quantity): All interviewees in both libraries believed that the eservices in the academic libraries assisted the learning process. However, regarding PAAET Library (PAAETL), participants acknowledged that the e-services in their libraries were limited. Therefore, all of them were unsatisfied with the e-services offered and wished to see extensive change in the current situation. One of them said:

"In fact, the e-services offered in our library are very few when compared with the number of library users. The library has only Online Public Access Catalogue (OPAC), Horizon System and LibraNet operating”.

On the other hand, the participants from Kuwait University library (KUL) confirmed that the eservices in their library were good and they were satisfied with them. One participant from KUL said:

"We are registered with 82 databases in different languages (English/Arabic) that cover all subjects in the university. Moreover, we have an operating system that can allow the users to search more than $10000 \mathrm{e}$ books and e-journals called Unified Search".

Although there were different points of views between the interviewees, participants in both libraries confirmed that KALs needs to benefit from the e-services' advantages including user familiarity, ease of use, and $24 / 7$ accessibility.

Smartphone Apps (SP-Apps): When participants were asked if they have SP-Apps in their libraries, all interviewees in both libraries confirmed that they did not have SP-Apps. However, one participant in KUL said:

"In 2013, we had planned to introduce an SP-App for the library, but unfortunately it was cancelled because there was not enough budget at that time". 
Also the participants from PAAETL said that there were attempts to design an SP-App, but the lack of budget was the main reason this was not accomplished. All participants believed that SP-App would be very important for their libraries, allowing users access to the e-services from any time and any place. Moreover, all own a smartphone and are familiar with its functions and applications.

\section{Financial context}

The Budget: Budget plays a major role to improve and develop library services. In fact, all the participants emphasised that budget is one of the most important factors that contribute to establishing and designing an SP-App for their libraries. However, most participants in both libraries confirmed that the main reason preventing the introduction of an SP-App in their libraries was lack of budget. Just one interviewee in KAL had another opinion:

"I think the budget is perfect and it could cover the SP-App project, but managing this budget unfortunately is not good".

\section{Management context}

Vision and Perception: The majority of interviewees already have plans to improve their libraries' services in order to meet users' needs. Regarding the SP-App, most of them confirmed the importance of introducing applications for their libraries. Therefore, one participant in KUL said:

"KUL has already begun work on this project, but the lack of awareness of library management and the lack of budget are the main reasons for the failure of the project".

According to the interviewees from PAAETL, currently there is no plan for an SP-App for their library and may be this or/and a similar study could give them a good visualisation to create an SPApp for their library.

Difficulties and Barriers: Although varied problems were illustrated above, the interviewees indicated other crucial difficulties currently facing their libraries with regard to the introduction of an SP-App. These are summarised below:

- A shortage of qualified individuals to manage this application.

- The refusal of some librarians to change and adapt to the new environment.

- Lack of budget.

- Lack of clarity about library management strategic objectives and vision for SP-Apps.

- Lack of library management awareness of the importance of SP-Apps in their libraries, which they do not view as a priority.

\section{THE MAIN FINDINGS}

Table 4 summarises the findings of the interview instrument by pattern code. It displays the iterative pattern codes derived from the interview instrument and assigns them to a scale (weak, adequate, and strong), according to the opinion of all interviewees.

Table 4: Interview Checklist Matrix

\begin{tabular}{|l|l|l|l|}
\hline Pattern Code & Weak & Adequate & Strong \\
\hline Electronic Services (quality \& quantity) & $\mathrm{X}$ & & \\
\hline Smartphone App & $\mathrm{X}$ & & \\
\hline Budget & $\mathrm{X}$ & & \\
\hline Vision and Perception & & $\mathrm{X}$ & \\
\hline
\end{tabular}


The analysis of interview data showed both common and different issues. For instance, the majority of interviewees expressed the need to introduce an SP-App to their library. They also confirmed that there are many difficulties in creating an SP-App including lack of budget, lack of awareness of library management, lack of clarity about library management strategic objectives, and vision for an SP-App. Table 4 shows that electronic services (quality and quantity), smartphone application, and budget are weak. Moreover, vision and perception are just adequate.

\section{RESEARCH DISCUSSION}

The purpose of this study was to investigate how Kuwaiti Academic Libraries (KALs) have responded to the rapidly evolving Smartphone-Apps (SP-Apps) environment, as well as exploring the level of electronic services provided in these libraries. According to the study's results, there were common points and unique points. Though the findings in the literature review, questionnaires, and interviews confirmed the importance of SP-Apps in academic libraries, KALs need more effort to improve this service. In the literature review section, studies and figures indicate the importance of applying SPApps in libraries in order to help end users find their needs as well as saving their time and effort. In the same vein, study participants, whether students or librarians, stressed that the SP-Apps in KALs has become an urgent need to develop and improve the services in their libraries.

In order to discuss the results of the study, it is necessary to answer the following research questions:

1. What is the users' satisfaction with e-services provided by governmental KALs?

In general, the results indicate that most users in governmental KALs are not satisfied with e-services provided by their libraries. However, when viewpoints are compared, KUL users are more satisfied than PAAETL users with the e-services offered. This finding shows that decision makers in KUL are seeking to provide better e-services to their users.

\section{What are the desired features of e-services in governmental KALs?}

The results confirm that governmental KALs need to improve their e-services, especially in the PAAETL as there was a clear lack of e-resources and services. This could be done if they benefit from other academic libraries' experiences, whether regionally or globally. The findings indicate that the most desired features of e-services in governmental KALs are:

- Users can access all e-services and e-resources including databases, e-journals and e-books.

- Users can ask a librarian directly.

- Users can find the latest news and events about the library.

- Users can search the library catalogue easily from anywhere.

- SP-Apps work on most popular operating systems such as IOS, Android.

- SP-Apps introduce new real-time information and services that support users in their academic programmes.

\section{Why is it important to establish an SP-App in governmental KALs?}

The findings confirm that SP-Apps have become essential for academic institutions and academic libraries in particular. For instance, the literature review indicated that many international and regional academic libraries such as Leeds University Library, Harvard University Library, UAE University Library, and King Fahad University Library have introduced these Apps to provide best services for their users. In the same vein, the study results show that most governmental KALs' users believe it is important to introduce an SP-App in their library for several reasons:

- $\quad$ It is very easy to use.

- $\quad$ Users can use it $24 / 7$.

- It saves time and effort obtaining information.

- It is familiar for most users. 
4. What are the main barriers, if any, that may hinder building an SP-App for KALs?

Dahlstrom et al. (2013) found that inadequate battery life, slow network connections, and device usability concerns were the top three limitations of using a smartphone as an academic tool. The present study results indicate that there are crucial difficulties facing governmental KALs' efforts to establish SP-Apps:

- A shortage of qualified individuals to manage this application.

- Some librarians' refusal to change and adapt to the new environment.

- $\quad$ Lack of budget.

- $\quad$ Lack of clarity about library management strategic objectives and vision for SP-Apps.

- Lack of library management awareness of the importance of SP-Apps, which they do not regard as a priority.

\section{CONCLUSION \& RECOMMENDATION}

The majority of studies confirm that it is very important to use SP-Apps in academic libraries. Furthermore, according to several studies, the new generation depends on the use of smartphones. For this reason, it was necessary in this study to investigate how governmental Kuwaiti Academic Libraries (KALs) have responded to the rapidly evolving SP-Apps environment, as well as to explore the level of e-services they provide. Unfortunately, the study results confirmed that the e-services of government KALs are limited and not satisfactory. In addition, the KALs still do not benefit from the features of SP-Apps like other academic libraries around the world such as the University of Leeds Library, Harvard University Library, Library of UAE, and Saudi Arabia. In this regard, the researchers present recommendations that may contribute to the introduction of SP-Apps for KALs:

1. The Ministry of Higher Education in cooperation with the KAL management should enact new policies, plans, and strategies to improve the e-services in their libraries. Especially in the PAAETL, where the study results confirmed that the e-services and resources were very limited and need to improve.

2. The successful theories and practices of SP-Apps in the higher education institutions and libraries of developed countries should be taken into account. Such practices have been fully tested for several years in different academic libraries. Adopting schemes already in existence would undoubtedly raise the credibility of the intended enterprises.

3. It is important to modify the current situation via raising the level of government support and increasing the annual budget for academic libraries of the authorities responsible for this issue as represented by the Ministry of Higher Education. This should be carried out in order to cope with tremendous global developments in information technology and communication as well as meet the needs of library users.

4. Designing SP-Apps that have reliable content and a user interface that is easy to use is a considerable challenge. For this reason, the study results highly recommends introducing SPApps for KALs as soon as possible.

While the study has provided new data about the SP-Apps in KALs, further aspects need to be considered in future research. The recommendations proposed are relevant to Kuwait. Further research may be useful in this field in other developing countries, in order to test or develop the suggested strategy. Moreover, the data and recommendations could be adopted for different scenarios, for example, different countries or other libraries. 


\section{REFERENCES}

Alosaimi, F., Alyahya, H., Alshahwan, H., Al Mahyijari, N., \& Shaik, S.A. (2016). Smartphone addiction among university students in Riyadh, Saudi Arabia. Saudi Medical Journal, 37(6), 675-683.

Bomhold, C. R. (2013). Educational use of smart phone technology: a survey of mobile phone application use by undergraduate university students. Program: Electronic Library and Information Systems, 47(4), 424-436.

Caperon, E. L. (2015). Developing adaptable, efficient mobile library services: Librarians as enablers. Ariadne, 73. Available at http://www.ariadne.ac.uk/issue73/caperon

Chen, B., \& Denoyelles, A. (2013). Exploring students' mobile learning practices in higher education. Educause Review. Retrieved 11 January 2016 from: http://er.educause.edu/articles/2013/10/exploring-studentsmobile-learning-practices-in-higher-education

Dahlstrom E., Walker, J. D., \& Dziuban, C. (2013). ECAR study of undergraduate students and information technology. Retrieved 6 February 2016 from https://net.educause.edu/ir/library/pdf/ERS1302/ERS1302.pdf

Douglas, D., \& Melody, C. (2012). Dictionary of computer and Internet terms. Barron's Educational Series.

Harvard University. (2016). Harvard mobile apps. Retrieved 21 January 2016from http://www.harvard.edu/aboutharvard/harvard-mobile-apps

Kuwait Government Online. (2015). E-government portal. Retrieved 5 January 2016 from http://www.e.gov.kw/sites/kgoEnglish/Portal/pages/portalmain.aspx

Kuzel, A. J., Engel, J. D., Addison, R. B., \& Bogdewic, S. P. (1994). Desirable features of qualitative research. Family Practice Research Journal, 14(4), 369-378.

Meier, A. (2010). Comparative analysis, mobile device user research. California Digital Library. Retrieved 11 January 2016 from https://wiki.ucop.edu/display/CMDUR/Home

Mills, K. (2009). M-libraries: Information use on the move. Arcadia Programme. Retrieved 11 February, 2016 from http://arcadiaproject.lib.cam.ac.uk/docs/M-Libraries report.pdf

Oates, O. (2006). Researching information systems and computing. London: Sage Publications.

UAE University. (2016). UAEU mobile app. Retrieved 29 March 2016 from http://www.uaeu.ac.ae/en/vc/uits/

Walsham, G. (1995). Interpretive case studies in IS research: Nature and method. European Journal of Information Systems, 4(2), 74-81.

Yin, R. K. (2009). Case study research, design and method (4th ed). Beverly Hills, CA: Sage Publications.

\section{BIOGRAPHIES}

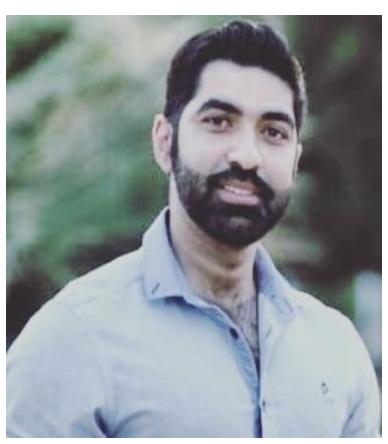

Dr. Husain F. Ghuloum is an assistant professor in Department of Library and Information Sciences (DLIS) in Public Authority for Applied Education \& Training (PAAET). He obtained his PhD from School of the Built \& Environment in Salford University in UK, MSc from Leeds Metropolitan University (Information Studies) in UK and BA from Public Authority for Applied Education \& Training, Department of Library And Information Sciences (DLIS) in Kuwait. His research interests are in the area of ICT in Academic Libraries, Digital Libraries, Electronic Libraries and Information Seeking Behavior. 


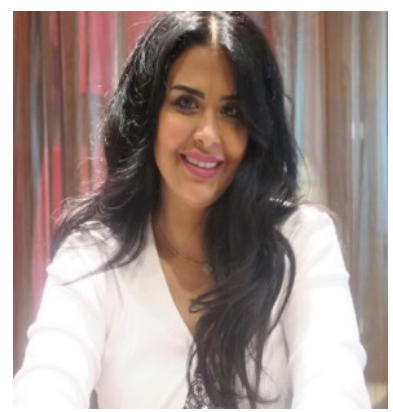

Dr. Zuwainah Al-lamki is an assistant professor in Department of Library and Information Sciences (DLIS) in Public Authority for Applied Education \& Training (PAAET). She obtained her PhD from Business school in Salford University in UK, MSc from Kuwait University (Library \& Information Science) in Kuwait and BA from Public Authority for Applied Education \& Training, Department of Library and Information Sciences (DLIS) in Kuwait. Her research interests are in the area of ICT in Libraries, Open Access and Cataloging. 